\title{
Correlation between antibodies and histology in celiac disease: Incidence of celiac disease is higher than expected in the pediatric population
}

\author{
PETER MAKOVICKY ${ }^{1}$, KVETOSLAVA RIMAROVA $^{2}$, ANDREJ BOOR ${ }^{3}$, \\ PAVOL MAKOVICKY ${ }^{4}$, PAVEL VODICKA ${ }^{5}$, GABRIEL SAMASCA ${ }^{6}$ and PETER KRUZLIAK ${ }^{7}$
}

${ }^{1}$ Department of Veterinary Sciences, Czech University of Life Sciences in Prague, CZ-165 21 Prague, Czech Republic; ${ }^{2}$ Institution of Public Health; ${ }^{3}$ Institution of Pathology, Pavol Jozef Safarik University in Košice, SK-040 11 Košice; ${ }^{4}$ Department of Biology, Selye Janos University, SK-945 01 Komarno, Slovak Republic; ${ }^{5}$ Department of the Molecular Biology of Cancer, Institute of Experimental Medicine, Academy of Sciences of the Czech Republic, CZ-142 20 Prague, Czech Republic; ${ }^{6}$ Institution of Immunology, Iuliu Hatieganu University of Medicine and Pharmacy, RO-400177 Cluj-Napoca,

Romania; ${ }^{7}$ Department of Pediatric Gastroenterology, Hospital in Zvolen, SK-960 01 Zvolen, Slovak Republic

Received April 1, 2013; Accepted July 23, 2013

DOI: $10.3892 / \mathrm{mmr} .2013 .1627$

\begin{abstract}
The present study aims to report on the correlation between the degree of negativity of anti-endomysial antibodies and anti-tissue transglutaminase antibodies in the $\operatorname{IgA}$ and $\operatorname{IgG}$ classes with regard to histological grade, in 44 newly diagnosed children with celiac disease (CD). Samples with negative antibodies, but a positive histology from a 5-year program searching for $\mathrm{CD}$ in the pediatric population were collected. A total of 4247 biopsy samples were used in this study. We documented that certain pediatric patients are seronegative, while the disease is active and the incidence of $\mathrm{CD}$ is higher than expected in the pediatric population. This is an important finding, which demonstrates the lack of association between autoantibodies and lesions, and justifies the use of biopsies for an accurate CD diagnosis and the importance of revising the diagnostic criteria in a clinical, endoscopic and serological context. We recommend a more active search for incidences of the disease in the pediatric population. Serological markers are not the main method for the diagnosis of CD as they are considered to only have a supporting role clinically. Biopsies of the small intestine are always necessary for the diagnosis of $\mathrm{CD}$ in these patients.
\end{abstract}

Correspondence to: Ing. Peter Makovicky, PhD, Department of Veterinary Sciences, Czech University of Life Sciences in Prague, 6 Suchdol, CZ-165 21 Prague, Czech Republic

E-mail: pmakovicky@email.cz

Key words: celiac disease, autoimmune disease, enterobiopsy, gluten-free diet, screening

\section{Introduction}

Non-invasive examination methods are increasingly important in diagnosing celiac disease (CD). New options for diagnosing $C D$ have been discovered as a result of progress in immunology (1). The detection of circulating autoantibodies is becoming more frequent clinically. As a result, many new, highly heterogeneous cases of $\mathrm{CD}$ have been diagnosed, and consequently, recognition of the incidence of $\mathrm{CD}$ in the pediatric and adult populations has increased. Detection of anti-endomysial antibodies (AEA) and anti-tissue transglutaminase antibodies (t-TG), characteristic for their high sensitivity and specificity, play important roles in diagnosing and clinically monitoring CD $(2,3)$. Nevertheless, histopathology remains the major tool for clinicians, and particularly gastroenterologists, for definitively diagnosing $\mathrm{CD}(4,5)$. A variety of studies have documented that AEA, and t-TG, are highly specific in predicting CD $(6,7)$. There are also seronegative data, which is particularly true for the adult population (8). The diagnosis in children is more successful (9), as pediatric CD has clear features in comparison to adult CD (10). It is often difficult to diagnose CD quickly, due to the fact that $\mathrm{CD}$ has a wide range of symptoms. However, we do not know if the same problems exist in the diagnosis of pediatric patients. We decided to test this hypothesis on a population of children in Eastern Slovakia. The objective of this study was to compare the levels of AEA and t-TG (IgA, IgG) in the plasma with that of histological abnormalities in pediatric patients with $\mathrm{CD}$.

\section{Materials and methods}

Patients. Between 2005 and 2010, a program which searched for $\mathrm{CD}$ in the pediatric population was performed. All samples were obtained from the Teaching Faculty Hospital (Košice, Slovakia). In total, 4,247 biopsy samples were used. Informed consent was provided by the parents of the children. 
This study was approved by the Ethics Committee of Pavol Jozef Safarik University in Kosice, Kosice, Slovak Republic.

Serum analysis. Sera from all children with digestive disorders and chronic non-specific gastroenteritis were sampled during hospitalization, in addition to routine biochemical investigations. Blood sera were separated using routine biochemical methodology (11). Serological testing kits were provided by INOVA Diagnostics (San Diego, CA, USA). AEA (IgA) and t-TG (IgA and $\operatorname{IgG}$ ) were examined using immunofluorescence and other immunological methods. For AEA examination, binding to human umbilical cord tissue was used and for t-TG we used the classical immunological ELISA test. AEA was investigated by indirect immunofluorescence neutrophil inhibitory factor (NIF), and the limit value for t-TG was $10 \mathrm{U} / \mathrm{ml}$. Only samples where AEA were negative were selected. Regardless of the outcome of the serology, biopsies from the duodenum were subsequently performed.

Biopsies. Each patient underwent between three to five endoscopic biopsies from the bulb and third duodenal portions and the samples were fixed in a $10 \%$ formalin solution. Duodenal biopsy specimens were obtained by standard procedures, including orientation, processing and interpretation in order to avoid, or minimize, their misinterpretation (12). The samples were hematoxylin \& eosin (H\&E) stained and evaluated in accordance with the Marsh-Oberhuber system $(13,14)$.

\section{Results}

Samples. From the 4,247 samples, we found 44 new cases of $\mathrm{CD}$ in children with AEA negativity, but these instances always coexisted with histological abnormalities of the small intestine (Table I). A t-TG (IgA) value $>10 \mathrm{U} / \mathrm{ml}$ was detected in 4 patients, and a t-TG $(\operatorname{IgG})$ value $>10 \mathrm{U} / \mathrm{ml}$ was detected in another 4 patients. All others t-TG $(\operatorname{IgA})$ and $\mathrm{t}-\mathrm{TG}(\mathrm{IgG})$ values were $<10 \mathrm{U} / \mathrm{ml}$. There was elevated $\mathrm{t}-\mathrm{TG}(\operatorname{IgA})$ or $\mathrm{t}-\mathrm{TG}(\operatorname{IgG})$, but none of the patients exhibited increases in both values. All values are in the context of the AEA negativity. As shown in the Table I, AEA negativity is always visible in Marsh I histological grade, as well as in the advanced grade of histological abnormalities, MIII. Values of t-TG (IgA) and t-TG (IgG) $>10 \mathrm{U} / \mathrm{ml}$ were visible only in the advanced Marsh III grade of histological abnormalities, remaining $<10 \mathrm{U} / \mathrm{ml}$ in histological grade Marsh I. Of the 44 samples, nine were diagnosed as Marsh I, two as Marsh IIIA, 14 as Marsh IIIB and 19 as Marsh IIIC. Variable damage, including inflammatory lesions with fine, or total, villous atrophy of the small intestine was visible in our investigated materials. In the cases with partial villous atrophy, the differentiated intraepithelial inflammatory florid process (Fig. 1) was visible as well. In cases where it was difficult to obtain a morphological image, which prevented the exact evaluation of mucous membrane characteristics, we were able to find only residual structures of crypts with compensatory cryptic hyperplasia and hyperplasia of Brunner's glands. Regarding the material characteristics, the main feature was severe structural disorder, resulting in completely smoothed mucous membrane relief, which consisted of mixed dense inflammation infiltrate with predominant intraepithelial lymphocytes and plasma cells (Fig. 2).
Table I. Overview of immunological evaluation values and associated histopathological description in pediatric CD.

\begin{tabular}{|c|c|c|c|c|}
\hline Patient & $\mathrm{t}-\mathrm{TG} \operatorname{Ig} \mathrm{A}$ & $\mathrm{t}-\mathrm{TG} \mathrm{IgG}$ & AEA & Marsh \\
\hline 1 & 2.6 & 3.8 & Negative & I \\
\hline 2 & 2.7 & 2.4 & Negative & I \\
\hline 3 & 1.0 & 1.6 & Negative & I \\
\hline 4 & 4.4 & 2.8 & Negative & I \\
\hline 5 & 2.7 & 2.5 & Negative & I \\
\hline 6 & 3.2 & 4.4 & Negative & I \\
\hline 7 & 1.0 & 5.4 & Negative & I \\
\hline 8 & 2.6 & 3.8 & Negative & I \\
\hline 9 & 2.7 & 2.4 & Negative & I \\
\hline 10 & 7.2 & 6.8 & Negative & M3A \\
\hline 11 & 7.1 & 4.2 & Negative & M3A \\
\hline 12 & 3.0 & 3.5 & Negative & M3B \\
\hline 13 & 2.6 & 4.9 & Negative & M3B \\
\hline 14 & 3.4 & 9.1 & Negative & M3B \\
\hline 15 & 2.5 & 1.4 & Negative & M3B \\
\hline 16 & 11.2 & 2.7 & Negative & M3B \\
\hline 17 & 7.8 & 7.3 & Negative & M3B \\
\hline 18 & 4.1 & 4.5 & Negative & M3B \\
\hline 19 & 1.0 & 1.8 & Negative & M3B \\
\hline 20 & 1.0 & 4.0 & Negative & M3B \\
\hline 21 & 3.0 & 3.5 & Negative & M3B \\
\hline 22 & 2.6 & 4.9 & Negative & M3B \\
\hline 23 & 3.4 & 9.1 & Negative & M3B \\
\hline 24 & 2.5 & 1.4 & Negative & M3B \\
\hline 25 & 12.2 & 2.7 & Negative & M3B \\
\hline 26 & 1.7 & 89.3 & Negative & M3C \\
\hline 27 & 2.5 & 4.8 & Negative & M3C \\
\hline 28 & 5.1 & 10.1 & Negative & M3C \\
\hline 29 & 6.1 & 3.5 & Negative & M3C \\
\hline 30 & 2.5 & 2.6 & Negative & M3C \\
\hline 31 & 2.4 & 6.9 & Negative & M3C \\
\hline 32 & 5.1 & 4.0 & Negative & M3C \\
\hline 33 & 17.2 & 4.8 & Negative & M3C \\
\hline 34 & 3.8 & 5.9 & Negative & M3C \\
\hline 35 & 8.3 & 8.0 & Negative & M3C \\
\hline 36 & 3.3 & 1.7 & Negative & M3C \\
\hline 37 & 2.7 & 3.9 & Negative & M3C \\
\hline 38 & 1.7 & 89.3 & Negative & M3C \\
\hline 39 & 2.5 & 4.8 & Negative & M3C \\
\hline 40 & 5.1 & 10.1 & Negative & M3C \\
\hline 41 & 15.6 & 8.2 & Negative & M3C \\
\hline 42 & 8.3 & 8.0 & Negative & M3C \\
\hline 43 & 3.3 & 1.7 & Negative & M3C \\
\hline 44 & 2.7 & 3.9 & Negative & M3C \\
\hline
\end{tabular}

$\mathrm{CD}$, celiac disease; AEA, anti-endomysial antibody; t-TG, anti-tissue transglutaminase antibody.

\section{Discussion}

In this study, we wanted to demonstrate the lack of association between autoantibodies and lesions in certain cases of 
pediatric CD. This may justify the necessity of biopsies for the accurate diagnosis of $\mathrm{CD}$. We show lesions, found in our samples, that are diagnostically important. The findings of Rostami et al (15) demonstrated that AEA have limited value in CD screening programs. Their sensitivity in patients with total villous atrophy (Marsh IIIC) was $100 \%$, but with partial atrophy (Marsh IIIA) the sensitivity of AEA decreased to $31 \%$. Furthermore, a high IgA t-TG titer correlates with the histopathological finding of Marsh IIIC $(16,17)$. Another study revealed that positive AEA are observed mostly in CD patients with severe tissue damage due to partial or total villous atrophy, but they have a low sensitivity in CD patients with partial villous atrophy in spite of the use of different substrates $(18,19)$. Additionally, a study by Tărmure et al $(20)$ demonstrated that in patients with Marsh I and Marsh II, the sensitivity of AEA was lower. These results demonstrated that the autoantibody titers may correlate with the damage to the small intestine. In our study, there have been negative antibodies with Marsh IIIC, demonstrating that serological screening is not $100 \%$ accurate for the diagnosis of CD. That serological tests would be negative was known for adult CD patients but was not previously known for pediatric CD patients. It is possible that clinical symptomatology is poor in certain children, while the disease remains active, and these diagnostic problems require a solution. Therefore, a biopsy must always be performed, so that an expert pathologist may accurately distinguish CD from other diseases (21).

The literature has provided evidence that AEA titers are the first to disappear following the introduction of a gluten-free diet, as CD is induced by gluten and related cereal proteins. Midhagen et al (22) demonstrated that antibody titers decreased sharply within the first month following the introduction of a gluten-free diet. It is possible that weak reactions of AEA or t-TG are caused by the ingestion of gluten-free food, but the degree of histological damage remains high. Fernández-Salazar et al (23) documented that AEA negativity is not rare in patients with $\mathrm{CD}$. These results demonstrate that sensitivity to serology varies according to the intestinal damage and the introduction of a gluten-free diet. The results of other studies also support this hypothesis $(24,25)$. Therefore, we recommend multiple endoscopic biopsies from the proximal and distal duodenum (26,27). Furthermore, in cases of low IgA t-TG titers or in patients with IgA deficiency, intestinal biopsies should remain mandatory (28). The results of certain studies have revealed that only patients with a IgA t-TG level $\geq 100 \mathrm{U} / \mathrm{ml}$ and whose symptoms improve upon the introduction of a gluten-free diet may not require a biopsy of the small intestine to confirm CD (29,30). Although these results are promising, in our opinion, biopsies should not be rejected. However, there are children who are AEA positive and exhibit a normal mucosal villous morphology of the small intestine, which indicates that the diagnostic criteria for CD should be re-evaluated (31). These disparities were described for other antibodies [e.g., AGA (IgA), ARA (IgA) and JAB (IgA)], which is also important for the pathologist to avoid rejection of biopsies based on insufficient evidence (32). Certain studies report that an accurate diagnosis is supported by the genetic analysis of HLADQ2 or HLADQ8 $(33,34)$, but these tests are not yet standard practice in all workplaces, and HLA association alone is inadequate for providing an

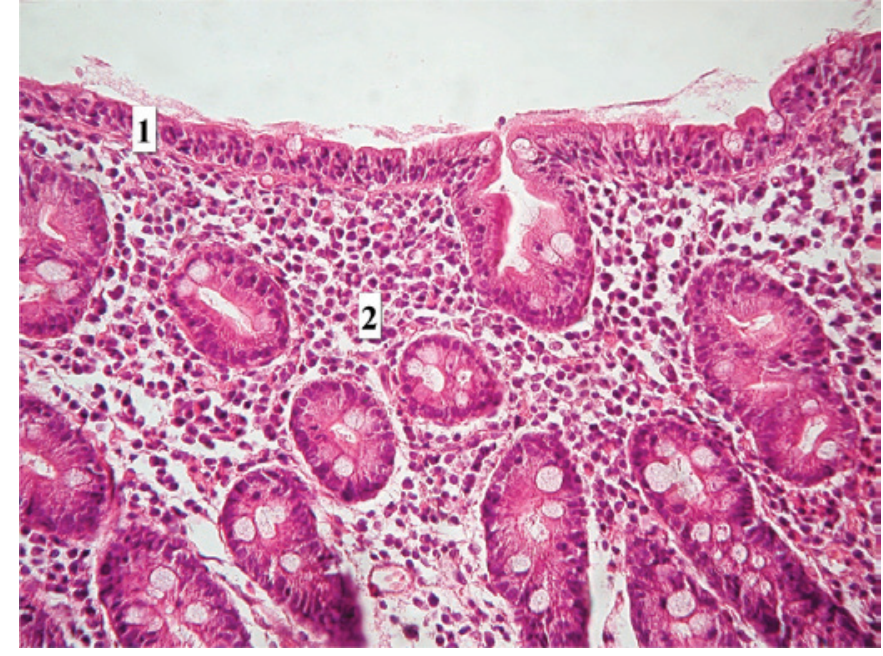

Figure 1. Section of the duodenum with total villous atrophy and well-activated inflammatory process throughout the mucosa. 1, epithelium; 2 , inflammatory process and plasmatic cells. Magnification, x200. H\&E, hematoxylin \& eosin

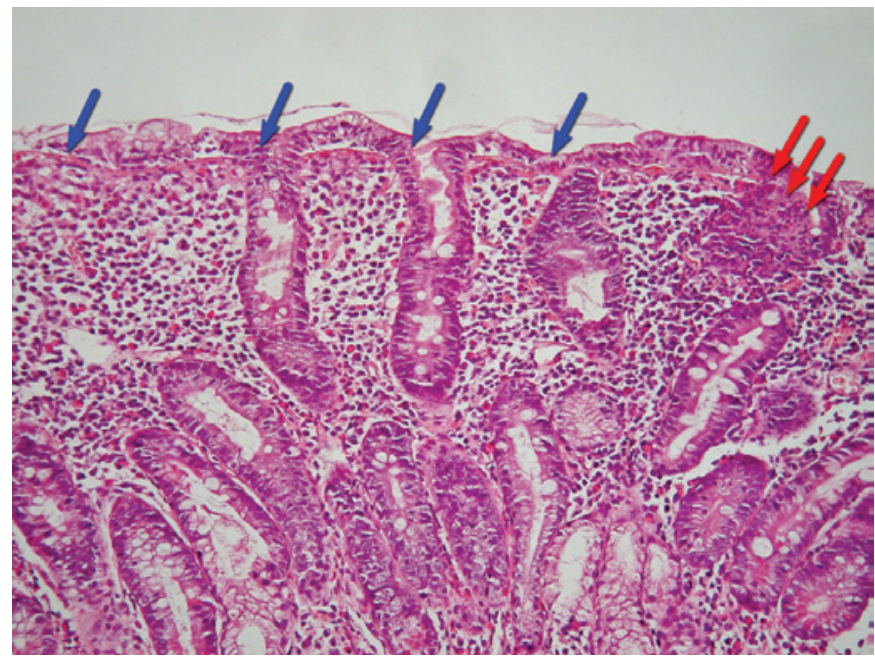

Figure 2. Sample with total villous atrophy (blue arrows) and epithelial erosion (red arrows), including inflammatory process of the small bowel. Magnification, x100. H\&E, hematoxylin \& eosin

explanation of the inheritance pattern. For children with a biopsy consistent with $\mathrm{CD}$, in addition to a positive response to a gluten-free diet, HLA testing is not required (35). Di Osdado et al (36) found variations in the expression levels of 109 genes by comparing Marsh III and Marsh 0 lesions, which have roles in the proliferation and differentiation pathways. These results are crucial and encouraging for medical practice, as they may lead to alternative future genetic analyses and the discovery of combinations with new candidate genes for $\mathrm{CD}$. Recent studies have focused on ways to speed up the diagnosis of CD $(37,38)$, but according to our study, biopsies remain necessary. Until we find a combination of diagnostic methods that are $100 \%$ reliable, we should continue to perform biopsies. We believe that currently biopsies are the optimum way for the gastroenterologist to accurately diagnose $\mathrm{CD}$ in at risk pediatric groups, as well as in children with unspecified long-term related digestive 
problems. Histological results are important for clinicians, but particularly for the gastroenterologist, in order to establish tests and interpret all available data $(39,40)$.

It has been many years since $\mathrm{CD}$ was considered to be a rare disease and experts have agreed that the incidence of $\mathrm{CD}$ will increase, since more programs have started to investigate the 'celiac iceburg' (41). Autoantibodies are considered to only be helpful in clinical practice, with regards to CD screening. In accordance with this, a biopsy of the small intestine is always required for the accurate diagnosis of $\mathrm{CD}$. We recommend a minimum of four endoscopic biopsies to be obtained from the bulb and third duodenal portions, as a section of the biopsy may be damaged, and the absence of certain material that should be investigated may result in incorrect histopathological interpretation. Slice descriptions should include all relevant information, and the histopathological report should be clear and conform to the recommended standards for intestinal biopsies. We consider this information to be particularly important for pathologists, which is in accordance with the views expressed in other studies (42). We recommend the use of autoantibodies only as a supportive method, as a control in gluten-free diets or as an early predictor of $\mathrm{CD}$ with necessary further follow-up. Recent European Society of Pediatric Gastroenterology, Hepatology and Nutrition (ESPGHAN) guidelines state that in cases where a child manifests clear symptoms of $\mathrm{CD}$ and demonstrates particularly high levels of t-TG, with positive HLA testing, the physician may consider omitting a biopsy. However, there are some instances where pediatric $\mathrm{CD}$ has remained undiagnosed, providing support for a revision to the diagnostic criteria in a clinical, endoscopic and serological context. However, since there are no reliable data on the incidence of $\mathrm{CD}$ in children in the East region of the Slovak Republic, our results may be considered to be valid for other countries as well, given that many countries have no screening, only local screening or use different diagnosis methods. The incidence of $\mathrm{CD}$ in pediatric patients is higher than previously assumed.

Recent and current literature indicates that celiac disease is underdiagnosed. From our results we conclude that the screening program should be considerably more intense, particluarly in pediatrics. In numerous cases it is difficult to diagnose only from the serum. Biopsies should be part of the investigation, regardless of the outcome of serology.

\section{Acknowledgements}

This study was supported by the IGA MZCR: NT 13424-4/2012 grant.

\section{References}

1. Samaşca G, Sur G and Lupan I: Current trends and investigative developments in celiac disease. Immunol Invest 42: 273-284, 2013.

2. Fasano A, Araya M, Bhatnagar S, et al: Federation of International Societies of Paediatric Gastroenterology, Hepatology, and Nutrition consensus report on celiac disease. J Pediatr Gastroenterol Nutr 47: 214-219, 2008.

3. Fric P, Gabrovska D and Nevoral J: Celiac disease, gluten-free diet, and oats. Nutr Rev 69: 107-115, 2011.

4. Bao F and Bhagat G: Histopathology of celiac disease. Gastrointest Endosc Clin N Am 22: 679-694, 2012.

5. Di Sabatino A and Corazza GR: Coeliac disease. Lancet 373: 1480-1493, 2009.
6. Chorzelski TP, Sulej J, Tchorzewska H, Jablonska S, Beutner EH and Kumar V: IgA class endomysium antibodies in dermatitis herpetiformis and coeliac disease. Ann NY Acad Sci 420: 325-334, 1983.

7. Dieterich W, Ehnis T, Bauer M, Donner P, Volta U, Riecken EO and Schuppan D: Identification of tissue transglutaminase as the autoantigen of celiac disease. Nat Med 3: 797-801, 1997.

8. Lindfors K, Koskinen O, Kurppa K, et al: Serodiagnostic assays for celiac disease based on the open or closed conformation of the autoantigen, transglutaminase 2. J Clin Immunol 31: 436-442, 2011.

9. Mariné M, Farre C, Alsina M, et al: The prevalence of celiac disease is significantly higher in children compared with adults. Aliment Pharmacol Ther 33: 477-486, 2011.

10. Rodrigo-Sáez L, Fuentes-Álvarez D, Pérez-Martínez I, et al: Differences between pediatric and adult celiac disease. Rev Esp Enferm Dig 103: 238-244, 2011 (Article in English and Spanish).

11. Samaşca G, Iancu M, Farcău D, et al: IgA anti-tissue transglutaminase antibodies, first line in the diagnosis of celiac disease. Clin Lab 57: 695-701, 2011.

12. Ravelli A and Villanacci V: Tricks of the trade: How to avoid histological pitfalls in celiac disease. Pathol Res Pract 208: 197-202, 2012.

13. Marsh MN: Gluten, major histocompatibility complex, and the small intestine. A molecular and immunobiologic approach to the spectrum of gluten sensitivity ('celiac sprue'). Gastroenterol 102: 330-354, 1992.

14. Oberhuber G, Granditsch G and Vogelsang H: The histopathology of coeliac disease: time for a standardized report scheme for pathologists. Eur J Gastroenterol Hepatol 11: 1185-1194, 1999.

15. Rostami K, Kerckhaert J, Tiemessen R, Blomberg BM, Meijer JW and Mulder CJ: Sensitivity of antiendomysium and antigliadin antibodies in untreated celiac disease: disappointing in clinical practice. Am J Gastroenterol 94: 888-894, 1999.

16. Arshad $\mathrm{H}$ and $\mathrm{Ahmad} \mathrm{Z}$ : Histologic findings in biopsies/resection specimens from the small intestine with special emphasis on celiac disease: experience from a developing country in South Asia. Ann Diagn Pathol 16: 436-440, 2012.

17. Vivas S, Ruiz de Morales JG, Riestra S, et al: Duodenal biopsy may be avoided when high transglutaminase antibody titers are present. World J Gastroenterol 15: 4775-4780, 2009.

18. Rostami K, Kerckhaert J, Tiemessen R, Meijer JW and Mulder CJ: The relationship between anti-endomysium antibodies and villous atrophy in coeliac disease using both monkey and human substrate. Eur J Gastroenterol Hepatol 11: 439-442, 1999.

19. Rostami K, Mulder CJ, Stapel S, et al: Autoantibodies and histogenesis of celiac disease. Rom J Gastroenterol 12: 101-106, 2003.

20. Tărmure S, Cristea A, Sămpelean D, Negrean V and Alexescu T: Serological and histological correlations in celiac disease. Rom J Intern Med 45: 263-268, 2007.

21. Anderson RP: Coeliac disease: current approach and future prospects. Intern Med J 10: 790-799, 2008.

22. Midhagen G, Aberg AK, Olcen P, et al: Antibody levels in adult patients with coeliac disease during gluten-free diet: a rapid initial decrease of clinical importance. J Intern Med 256: 519-524, 2004.

23. Fernández-Salazar LI, de la Torre Ferrera N, Velayos Jiménez B, et al: Diagnostic problems in adult celiac disease. Rev Esp Enferm Dig 100: 24-28, 2008 (In Spanish).

24. Abrams JA, Diamond B, Rotterdam H and Green PH: Seronegative celiac disease: increased prevalence with lesser degrees of villous atrophy. Dig Dis Sci 49: 546-550, 2004.

25. Nachman F, Sugai E, Vázquez $\mathrm{H}$, et al: Serological tests for celiac disease as indicators of long-term compliance with the gluten-free diet. Eur J Gastroenterol Hepatol 23: 473-480, 2011.

26. Prasad KK, Thapa BR, Nain CK and Singh K: Assessment of the diagnostic value of duodenal bulb histology in patients with celiac disease, using multiple biopsy sites. J Clin Gastroenterol 43: 307-311, 2009.

27. Webb C, Halvarsson B, Norström F, et al: Accuracy in celiac disease diagnostics by controlling the small-bowel biopsy process. J Pediatr Gastroenterol Nutr 52: 549-553, 2011.

28. Clouzead-Girard H, Rebouissoux L, Taupin JL, et al: HLA-DQ genotyping combined with serological markers for the diagnosis of celiac disease: Is intestinal biopsy still mandatory? J Pediatr Gastroenterol Nutr 52: 729-733, 2011.

29. Donaldson MR, Book LS,Leiferman M,Zone JJ and Neuhausen SL: Strongly positive tissue transglutaminase antibodies are associated with Marsh 3 histopathology in adult and pediatric celiac disease. J Clin Gastroenterol 42: 256-260, 2008. 
30. Mubarak A, Wolters VM, Gerritsen SA, Gmelig-Meyling FH, Ten Kate FJ and Houwen RH: A biopsy is not always necessary to diagnose celiac disease. J Pediatr Gastroenterol Nutr 52: 554-557, 2011.

31. Kurppa K, Ashorn M, Iltanen S, Koskinen LL, Saavalainen P, Koskinen O, Mäki M and Kaukinen K: Celiac disease without villous atrophy in children: a prospective study. J Pediatr 157: 373-348, 2010.

32. Vega F, Chang CC, Schwartz MR, Preti HA, Younas M, Ewton A, Verm R and Jaffe ES: Atypical NK-cell proliferation of the gastrointestinal tract in a patient with antigliadin antibodies but not celiac disease. Am J Surg Pathol 30: 539-544, 2006.

33. Tikkakoski S, Savilahti E and Kolho KL: Undiagnosed coeliac disease and nutritional deficiencies in adults screened in primary health care. Scand J Gastroenterol 42: 60-65, 2007.

34. Lowichik A and Book L: Pediatric celiac disease: clinicopathologic and genetic aspects. Pediatr Dev Pathol 6: 470-483, 2003.

35. Rizkalla NR, Dixit R, Simpson S and Green PH: Celiac disease in children: an old disease with new features. Minerva Pediatr 64: 71-81, 2012.
36. Di Osdado B, Wapenaar MC, Franke L, et al: A microarray green for novel candidate genes in coeliac disease pathogenesis. Gut 53: 944-951, 2004

37. Brusca I, Carroccio A, Tonutti E, et al: The old and new tests for celiac disease: which is the best test combination to diagnose celiac disease in pediatric patients? Clin Chem Lab Med 50: 111-117, 2011.

38. Högberg L and Stenhammar L: Celiac disease: Pediatric celiac disease - is a diagnostic biopsy necessary? Nat Rev Gastroenterol Hepatol 9: 127-128, 2012.

39. Steele R and CRF: Diagnosis and management of coeliac disease in children. Postgrad Med J 87: 19-25, 2011.

40. Villanacci V, Ceppa P, Tavani E, et al: Coeliac disease: the histology report. Dig Liver Dis 43: S385-S395, 2011.

41. Sapone A, Bai JC, Ciacci C, et al: Spectrum of gluten-related disorders: consensus of new nomenclature and classification. BMC Med 10: 13, 2012.

42. Bao F, Green PH and Bhagat G: An update on celiac disease histopathology and the the road ahead. Arch Pathol Lab Med 136: 735-745, 2012. 